\title{
Can Agro-dealers Deliver the Green Revolution in Kenya?
}

\author{
Hannington Odame and Elijah Muange
}

\begin{abstract}
Kenya is in many ways the 'poster child' for Africa's new Green Revolution, with numerous public-private partnerships promoting agricultural innovation and rural entrepreneurship through a growing network of agro-dealers. Despite numerous claims that the agro-dealer model offers the best approach for delivering new seeds and other modern technologies to the country's small producers, this article highlights how reality on the ground has yet to match expectations. Drawing on surveys of agro-dealers in two contrasting agricultural districts and interviews with key informants, it shows how, despite considerable investment by a range of public and private actors, agro-dealers remain spread unevenly across the country and are inevitably concentrated in the higher potential agricultural areas. The changing structure of the Kenyan seed industry and the entry of large multinational and philanthropic players - who are focusing mainly on delivery of hybrid maize and fertilisers - are shifting this dynamic further. This approach is acting to narrow the choice of seeds and crop types to farmers in all areas.
\end{abstract}

\section{Agro-dealers and green revolutions}

In a bid to return the country to food selfsufficiency, the Government of Kenya has been spearheading strategies for a new 'Green Revolution' in the food producing sector, as spelt out in its Strategy for Revitalizing Agriculture (SRA), a ten-year action plan launched in 2004, and entrenched in its Vision 2030, the country's framework for long-term investment and development (Republic of Kenya 2007; 2004). ${ }^{1}$ Key among these strategies is the increased generation, promotion and use of modern farming inputs and technologies, particularly improved seed and fertiliser. Small-scale, independent stockists or input distributors, commonly known as 'agro-dealers', are seen to have a crucial role to play in distributing these inputs in a liberalised economy. As key actors in the Green Revolution agenda, agro-dealers are thus at the centre of current policy debates about the future of Kenya's seed system.

This article charts the rise of agro-dealers in recent national policy debates on agricultural innovation and food security and explores how they command a central position in new efforts to spark a smallholder-led revolution, asking:
Can agro-dealers really deliver the Green Revolution in Kenya? Drawing on key informant interviews and surveys of agro-dealers in two districts, Machakos in Eastern Province and Uasin Gishu in Rift Valley Province, it assesses the different politics and interests at play and the implications these raise for future investments in both formal and informal seed systems and the promotion of agro-dealers as catalysts of change in the agricultural sector.

\section{Delivering the technologies for the new Green Revolution \\ Different input channels have been used to deliver the various agricultural technologies to Kenya's 3 million smallholder farms. The main ones include public institutions, such as state corporations and public extension services; commercial channels, such as private seed companies and their networks of distributors; and charitable organisations, including donor agencies, non-governmental organisations (NGOs) and relief agencies. In recent years, the main actors and channels have changed with the shift from a public input distribution system to a more liberalised system. But, as we will see, while the array of actors involved in input}


provision has grown enormously, the vision of how inputs should be delivered has narrowed to a single, dominant model: the private, independent, agro-dealer.

Through most of the 1970s and 1980s, the public sector managed the input distribution and information dissemination system, controlling seed variety development and production and pricing and marketing of inputs (Argwings-Kodhek, Kwamboka and Karin 2004). The main actors in the cereal inputs arena were the Kenya Agricultural Research Institute (KARI), which was mandated to develop new crop varieties and implement the seed industry laws; the Kenya Seed Company (KSC), which produced and distributed the new cereal varieties developed by KARI; the Kenya Farmers Association (KFA), later renamed the Kenya Grain Growers Cooperative Union (KGGCU), which procured and distributed fertilisers and other inputs, and acted as an agent for KSC; the Agricultural Finance Corporation (AFG), which advanced inputs credit to farmers and the National Cereals and Produce Board (NCPB), which bought cereal grain from producers and recovered input credit advanced to farmers on behalf of AFG.

This system mostly benefited the large-scale cereal producers and farmers in high rainfall areas, who were also well served by good infrastructure, particularly in the Rift Valley and Central Kenya (Freeman and Omiti 2003; Nyangito 2008). In the mid-1980s, however, mismanagement and political interference at KGGCU resulted in inefficiencies that brought down this system (Nyoro 2002). The failure of the public distribution system triggered the push for liberalisation of the cereal input sector as part of the structural reforms imposed by the World Bank and International Monetary Fund (IMF). In 1990, the government continued this reform process by abolishing import quotas and licences and deregulating prices in the fertiliser industry (Omamo and Mose 1999). The liberalisation policies also allowed traders to break down the traditional $50 \mathrm{~kg}$ bags into smaller packets, in the hope that this would spur the use of fertiliser and increase productivity among smallholder farmers (Freeman and Omiti 2003). In 1996, the seed industry became fully liberalised and an autonomous industry regulator, the Kenya Plant Health Inspectorate Services (KEPHIS), was established to take over the regulatory role from KARI.
Economic liberalisation policies were meant to pave the way for a market-based economy, in which the private sector would take over functions such as input distribution from the state. Private companies and urban and rural traders entered the input supply market, dismantling the monopolistic network of public actors in input distribution in most parts of the country. However, market development has been slow due to capital constraints, complex trade and licensing arrangements and restrictive domestic laws in the seed industry. This has led to inadequate competition and high input prices, constraining the adoption of improved technologies by poor smallholder farmers, especially in low rainfall areas. As the next section will reveal, the government is not about to exit from input distribution just yet. In fact, there have been calls for African governments to facilitate access to inputs by resource-poor smallholder farmers through input subsidy programmes similar to the one developed in Malawi (see Chinsinga, this IDS Bulletin). Thus, rather than withdraw from the sector, the Government of Kenya has remained actively involved in input provision, with backing from the Alliance for a Green Revolution in Africa (AGRA), an international NGO supported by the Bill \& Melinda Gates Foundation and Rockefeller Foundation, the Food and Agriculture Organisation of the United Nations (FAO) and the World Bank.

Since the mid-2000s, a strong coalition of actors has emerged in Kenya with a focus on stimulating a new Green Revolution through the application of new technologies, particularly certified seeds and fertilisers, delivered by the public and private sectors (both multinational and local seed companies) with backing from the state, donors and philanthropic organisations. This core actor network sees agro-dealers as central to these delivery systems. In Kenya's Strategy for Revitalising Agriculture, for instance, one of the government's policy measures for improving farmers' access to inputs is to: 'assist stockists [agro-dealers] to increase the capacity for inputs supply and the provision of information... to farmers' (Republic of Kenya 2004). The ambitious, if somewhat unrealistic, target was to have stockists providing input services in at least 80 per cent of all small towns by 2007 .

Similar calls to develop agro-dealers have been made by various individuals and organisations. 
Table 1 Key AGRA-funded agro-dealer development projects in Kenya

\begin{tabular}{|c|c|c|}
\hline Organisation & Project purpose & Amount (US\$) and duration \\
\hline $\begin{array}{l}\text { Citizens Network for Foreign } \\
\text { Affairs Inc. }\end{array}$ & $\begin{array}{l}\text { To develop national agro-dealer networks to } \\
\text { improve access to agricultural inputs by } \\
\text { small-scale farmers. }\end{array}$ & $\begin{array}{l}\text { US\$4,473,851 } \\
1 \text { June } 2007 \text { to } 31 \text { May } 2010\end{array}$ \\
\hline $\begin{array}{l}\text { Citizens Network for Foreign } \\
\text { Affairs Inc. }\end{array}$ & $\begin{array}{l}\text { To develop the business and technical capacity } \\
\text { of agro-dealers and regional wholesalers. }\end{array}$ & $\begin{array}{l}\text { US\$194,505 } \\
1 \text { March } 2007 \text { to } 30 \text { June } 2007\end{array}$ \\
\hline Equity Bank Ltd. & $\begin{array}{l}\text { For a guarantee fund to facilitate access to } \\
\text { credit facilities by poor smallholder farmers, } \\
\text { agro-dealers and other players in the } \\
\text { smallholder farming value chain in Kenya.* }\end{array}$ & $\begin{array}{l}\text { US } \$ 2,500,000 \\
1 \text { May } 2008 \text { to } 30 \text { April } 2012\end{array}$ \\
\hline
\end{tabular}

Source Compiled from AGRA's website: www.agra-alliance.org/Map/Kenya.pdf (accessed 30 April 2011).

*This project is implemented in partnership with IFAD, www.agra-alliance.org/content/news/detail/822

For example, during the Africa Fertiliser Summit held in Nigeria in June 2006, Lennart Båge, the then President of the International Fund for Agricultural Development (IFAD), called on various actors to expand agro-dealer networks across the continent:

We see the emergence of a new rural private sector, with agro-dealers starting to provide farmers with inputs... Farmers' physical access to fertilizers is improving, largely due to the growth of agro-input dealer networks across rural Africa. But this work has to be scaled up through collaboration between governments, fertilizer suppliers, NGOs, farmers' organizations and international development agencies. (IFAD 2006)

In line with the appeal to scale-up agro-dealer networks, AGRA has established its Agro-dealer Development Programme (ADDP), which is being promoted in Kenya and several other African countries. AGRA asserts that 'a strong agro-dealer system is crucial to farmers' success because these local retailers serve as the primary conduits of farm inputs such as seeds and soil nutrients, and knowledge about their safe and efficient use' (AGRA 2009b). By August 2010, about US $\$ 7.2$ million had been committed by AGRA for ADP activities in Kenya (AGRA 2010). These include development of national agrodealer networks and credit guarantees to improve access to agricultural inputs by agrodealers and small-scale farmers.

For its part, the Government of Kenya, through the Ministry of Agriculture (MOA), is implementing its own input support programme, the National Accelerated Agricultural Input Access Program (NAAIAP), at an estimated cost of Ksh16.7 billion ( $\sim$ US $\$ 19.2$ million). ${ }^{2}$ This also involves a capacity building component for agrodealers, as well as the supply of subsidised inputs (particularly improved maize seed and fertilisers) through agro-dealers to poor farmers.

The next section will examine the ADDP and NAAIAP programmes and draw on lessons from the Machakos and Uasin Gishu field studies to assess their activities and preliminary outcomes for both small farmers and agro-dealers alike.

\subsection{AGRA's Agro-dealer Development Programme}

Since 2006, AGRA has been championing agricultural development in Kenya, among other African countries. The main participation of the organisation in cereal seed systems is through its Programme for Africa's Seeds Systems (PASS). The mission of PASS is to increase small-scale farmers' income and reduce poverty through increasing the farmers' yields. It is expected that more than 1,000 new varieties of at least ten staple crops that increase the productivity of Africa's small-scale farmers and contribute to the alleviation of the hunger and extreme poverty of 30-40 million people will be introduced in ten years, and participating smallscale farmers will be planting improved seeds on 20-30 per cent of their cultivated lands (AGRA 2010; 2009a,b; Rockefeller Foundation 2009).

PASS is implemented under four subprogrammes. Among these is the Agro-dealer Development Programme, which provides 
training, capital and credit to establish certified agro-dealers, who are a seen as a primary conduit of seeds, fertilisers and knowledge to smallholder farmers to increase their productivity and incomes (Table 1). Funded to the tune of about US $\$ 7.2$ million, the programme aims to build and develop networks of certified agro-dealers, to enhance the quality, volume and range of seeds sold. The ADDP is hoped to result in well-functioning agro-dealers in order to support a significant increase in the adoption of improved crop varieties.

ADDP activities build upon earlier work started by the Rockefeller Foundation in 2001 under its programme entitled 'Developing Rural Agricultural Input Supply Systems for Farmers in Africa'. The programme was informed by a narrative that traced low productivity of smallholder farmers in Africa to a lack of access to affordable agricultural inputs occasioned by poorly developed and weakly performing private sector input markets that assumed functions previously performed by the public sector, following structural adjustment and economic liberalisation. It stressed the need for a public-private partnership to raise awareness about improved technologies and inputs and create a high demand for the inputs; lower the transaction costs of supplying rural areas with agricultural inputs; improve the linkages between importers, wholesalers and retailers; and improve the economies of scale in marketing of inputs at the wholesale and retail levels.

The programme's activities were: training of rural stockists on knowledge of fertilisers and seeds, book-keeping, costing and pricing, managing business relations, sales and marketing, stock management and managing working capital. Once completed, these stockists became certified as 'agro-dealers'. This was aimed at enabling the stockists to provide farmers with credible information on agricultural inputs use. The certified agro-dealers would then be linked to major agricultural input supply firms for: credit arrangements; packing and selling seeds and fertilisers in small packages and form themselves into 'purchasing groups' and 'agrodealer associations', which allow them to better negotiate for lower prices and better credit financing arrangements with the agricultural input supply companies, and influence government policies on imports, pricing, distribution and marketing of agricultural inputs.
In Kenya, the ADP is implemented by the Agricultural Market Development Trust (AGMARK), a Kenyan organisation affiliated with Citizens Network for Foreign Affairs Inc. (CNFA) (a US NGO) in partnership with Equity Bank Ltd. (a national bank), the MOA and input supply companies, among others. Pilot activities were implemented in Western Kenya, where use of productivity enhancing inputs and market penetration of input supply companies was low, despite the area having good rainfall and soils. The programme encouraged input supply companies to venture into this region by absorbing part of the market development costs through sponsoring small field demonstrations with the inputs and organising input fairs in the rural areas where input suppliers would meet farmers and promote their products. After about three years, these efforts led to an influx of input marketing companies into the region and increased demand for modern inputs by smallholder farmers.

In June 2007, CNFA/AGMARK out-scaled its activities and started implementing a three-year programme known as the Kenya Agro-dealer Strengthening Program (KASP) funded by AGRA under the ADP. The main activities under KASP include: implementing agro-dealer surveys and mapping; facilitating access to financial credit for business start-up and stocking; conducting agro-dealer training; generating demand for farm inputs through field demonstrations, field days and agricultural shows; developing agro-dealer output marketing; promoting a farm inputs savings and loan programme among smallholder farmers and supporting formation of agro-dealer associations. KASP is implemented in 64 districts in six provinces (Nairobi and North Eastern Provinces are excluded).

As at January 2010, GNFA/AGMARK had supported the establishment of more than 81 new agro-dealers in areas with inadequate agrodealership and trained 2,166 agro-dealers, of which about 1,600 were actively participating in its activities. The organisation had also facilitated agro-dealers to form an umbrella association, the Kenya National Agro-dealer Association (KENADA), and was assisting the association to develop a business plan. In addition, over 20 agro-dealers had been supported to establish output marketing units, 
an innovative complement to the traditional role of farm input dealership. Through KASP,

CNFA/AGMARK expects to establish a network of sustainable agricultural input suppliers serving over 860,000 smallholder farmers by the end of the project's third year.

Although the project is still ongoing, and some districts have yet to be covered, preliminary results from the two study districts indicate that agro-dealers based in high potential areas have benefited more than those in low rainfall areas, with 48 per cent of interviewed agro-dealers having been trained in Uasin Gishu compared with only 10 per cent in Machakos. Further, the trainings seem to have disproportionately benefited the larger (wealthier) agro-dealers, with value of stock (a proxy for agro-dealer size) averaging about Ksh600,000 ( US\$7,160) for trained dealers compared to Ksh125,000 ( US $\$ 1,490)$ among those yet to be trained. An area for further investigation is the constraints that limit agro-dealer participation in these trainings, with a view to informing design of future programmes and improving participation particularly of the smaller agro-dealers.

\subsection{The Ministry of Agriculture's NAAIAP Programme} In 2006-07, the Government of Kenya formulated its NAAIAP Programme, which was expected to be implemented in 45 districts over three years, at a cost of approximately Ksh37 billion ( US\$441 million), which framed Kenya’s food security 'crisis' in terms of low soil fertility and poor access to key agricultural inputs, particularly improved seeds and fertilisers:

[R] esource-poor farmers do not have the know-how and cannot afford the cost of these inputs. The consequence is that soils are depleted of nutrients, and farmers obtain low yields. This is the main cause, not only of declining agricultural productivity, but also of increasing food insecurity and abject poverty... [T] hese farmers are so resourcepoor that without external intervention they will never be able to use these inputs. They will remain poor and would not be able to participate in farming as a commercial enterprise. This implies that the country will continue to have a high proportion of its people living below absolute poverty levels and facing food insecurity to the extent that they have to depend on relief food... The only way this section of the population can come out of the cycle of poverty and food insecurity is for them to be assisted with agricultural inputs for a given period of time with comprehensive training and capacity-building programmes.

(Republic of Kenya 2009)

The primary objective of the NAAIAP programme is therefore to improve access to seeds and fertiliser and increase the affordability of these key inputs for smallholder farmers to enhance food security and generate income through the sale of surplus produce. Ultimately, the programme is aiming to improve productivity and output at farm level for 2.37 million smallholder farmers with one hectare or less of land, by first mobilising farmers' resources and promoting efficiency in their utilisation and investment in agriculture by facilitating access and utilisation of farm inputs for increased production and poverty reduction (Republic of Kenya 2009).

As outlined in its Design and Implementation Framework (Republic of Kenya 2009), NAAIAP uses a two-pronged approach to achieve its objectives: the Kilimo Plus (Agriculture Plus) Starter Kits (input grants) and the Kilimo Biashara (Agriculture Business) Package (small business development packs). The Kilimo Plus starter kits target the very resource-poor subsistence farmers in districts with reliable rainfall who own less than 2.5 acres of land. The farmers are provided with a grant for basic inputs (mainly certified seed and fertiliser) to cover at least one acre of maize (this includes $10 \mathrm{~kg}$ of certified seed, one bag of a base dressing fertiliser and one bag of a top-dressing fertiliser). The grants are administered through a voucher system, which enables farmers to get inputs from agro-dealers, trained and accredited for the purpose. ${ }^{3}$ After supplying the inputs, agrodealers then redeem the vouchers from the government. Target farmers form themselves into groups, which facilitate training and ensure that inputs provided are utilised and part of the produce realised is channelled through the groups' cereal banks for sale to finance inputs for subsequent seasons.

After one season, these farmers are expected to increase production from an average of five $90 \mathrm{~kg}$ bags per acre to about 15 bags per acre. Assuming an average family size of seven persons, seven bags are adequate for annual 
consumption, while the remaining eight bags can be sold and ploughed back in form of improved inputs or expanded production. ${ }^{4}$ This way, the resource-poor farmers can graduate to next category and participate in Kilimo Biashara. This package targets farmers with better resource endowment and engaged in economically viable enterprises, but lacking basic farming inputs. Through this package, farmers are provided with basic inputs at cost and subsidised credit from financial institutions and facilitated (in terms of training and technical assistance) to continue with their enterprises. ${ }^{5}$

The implementation of NAAIAP has generated mixed results. By adopting an international narrative that links low productivity to degraded soils and lack of access to modern inputs (specifically fertilisers) and making it the national narrative in Kenya is inappropriate, since it ignores important regional agroecological and sociocultural variations. Actors in different parts of the country have different narratives about food production constraints in their regions. During our fieldwork in Machakos District, for example, extension officers cited poor rainfall as the main cause of low food production and hence food insecurity. They also identified that low use of farm inputs such as certified seeds and fertilisers was due to high prices. Yet they also pointed out that most farmers are poor, lack of access to agricultural credit, have an over-reliance on maize at the expense of other drought tolerant crops, as the other main food production constraints. ${ }^{6}$ Similarly, farmers cited low and erratic rainfall as the main challenge, but also mentioned frequent droughts; lack of basic farming implements (particularly for land preparation and soil and water conservation); few extension staff, as well as the high cost of improved seeds and fertiliser, as the main causes of low food production and food insecurity in the region. ${ }^{7}$

These arguments complement findings of several earlier studies that linked low adoption of improved seeds and fertilisers in low rainfall areas to risk-averse behaviour due to concerns about the unreliability of rainfall rather than lack of access to inputs (e.g. Kibaara et al. 2009; Freeman and Omiti 2003; Owuor 1999). In such areas, it is argued, inadequate soil moisture renders yields of most crops unresponsive to inorganic fertiliser use and in some cases the fertiliser may even harm the crop by burning it. This limits widespread use of certified seeds and fertilisers in those complex, risk-prone environments.

In contrast, in Uasin Gishu, a high rainfall district, MOA extension staff and farmers were in agreement that food security is normally not a problem in the area. They were also in agreement that, despite the high food production in the district, productivity (particularly of maize) was below potential levels. ${ }^{8}$ The main constraints to higher yields identified by extension workers were high cost of farm inputs; particularly fertiliser, diesel and labour; poor farming practices, such as late land preparation, weeding and pest control; and unpredictable weather patterns, particularly the onset of rains. Farmers cited low use of improved inputs (particularly fertiliser) due to high prices and poverty among farmers; and late planting as the main constraints to achieving high maize yields.

Second, the choice of maize as the only cereal crop to be promoted under the programme seems to negate farmers' preferences, especially in the low rainfall areas. In these areas, agriculture is highly diversified, not only as a strategy for mitigating environmental risks, but also because it offers a wide range of choice of crops that meet the dietary needs of the communities. Interviews with senior officials in the MOA identified diversification away from maize as 'the key' to addressing the problem of food insecurity, which is common in low rainfall areas. Farmers in Machakos District, especially those with very small farms, complained that they did not plant 'pigeon pea', a popular legume, because they had devoted all their land to a monocrop of NAAIAP maize, contrary to their usual practices. Focusing on maize to the exclusion of all other potential crops is an example of a 'one-size-fits-all' policy that may actually serve to undermine the very national food security goals the programme was meant to achieve. There is a need to investigate whether the programme would be more beneficial to farmers (especially in low rainfall areas) if they have the liberty to choose seed from a basket of key cereal and leguminous crops.

Third, there was a problem of beneficiary targeting at two levels. At the national level, the districts chosen for the project were those identified as having reliable rainfall or irrigation 
facilities. This means that farmers and agrodealers in low rainfall areas would be excluded from the programme. It could also be an indirect concession by the programme designers that the role of agro-dealers in spurring a Green Revolution in Kenya's Arid and Semi-Arid Lands (ASAL) is insignificant, even though they are home to the majority of the country's food insecure households and cover 80 per cent of the country's land area. At the local (district) level, identification of beneficiaries proved to be challenging, especially in higher rainfall areas where poverty levels are generally lower. Due to the short period of time allocated for identification of beneficiaries, village elders and assistant chiefs played a big role in identifying beneficiaries at community level. This resulted in nepotism, with some non-resource-poor farmers benefiting at the expense of deserving resource-poor farmers.

Fourth, the assumption that surplus maize will be harvested in Eastern Kenya is highly questionable because of the unreliability of rainfall in most areas. Machakos did not even harvest enough maize grain to meet their food requirements in the 2008/09 season.

Furthermore, the assumption that poor smallholder farmers will use proceeds from the sale of surplus maize grain to buy inputs for the subsequent season or to expand their farming business is not guaranteed. This is because many of the farmers, due to poverty and a lack of alternative income sources, are likely to use the money to meet other priority needs such as school fees and medical expenses.

As for the outcomes, about 21,500 farmers had already benefited from the inputs grant by September 2009, and yet the target for 2009/10 season was 170,000 farmers. In addition, 156 agrodealers had participated in supplying inputs to farmers. However, due to weaknesses in programme design and implementation challenges, there were winners and losers. Farmers in high rainfall areas seem to have benefited more from the project as opposed to their counterparts in low rainfall areas, largely due to differences in rainfall patterns between the two regions.

Similarly, agro-dealers in high rainfall areas benefited more than those in low rainfall areas. For instance, many more agro-dealers were trained in high-potential Uasin Gishu than in lowpotential Machakos (48 per cent vs. 10 per cent of those interviewed). Further, agro-dealer participation in input supply was more in Uasin Gishu (40 per cent) than in Machakos (3 per cent). In both regions, large-scale agro-dealers benefited more than small-scale agro-dealers (at the time of the survey, agro-dealers who had participated in supplying inputs had stock valued about Ksh870,000, while the stock of non-participating agro-dealers averaged about Ksh100,000).

In summary, NAAIAP was designed with the agro-dealer as a service delivery hub, but participation of agro-dealers so far in the study districts was both low and skewed. This is the result of a number of factors. First, those who do not meet the minimum qualifications such as registration with relevant authorities are locked out. This affects a larger proportion of agrodealers in Machakos, where there is a smaller percentage of legal agro-dealers than in Uasin Gishu'. Second, there is a lack of capacity in terms of working capital or business relationships to secure credit arrangements for purchasing the inputs, and vehicles to transport inputs to farming communities. Again, the constraint is more intense in Machakos, where a larger proportion of agro-dealers operate at a very small scale. Third, tedious procedures and delays in redemption of vouchers from the government by participating agro-dealers (it took 3-6 months to be repaid after supplying inputs) jeopardises credit arrangements and business relations between agro-dealers and input suppliers/financiers and this discourages some agro-dealers from participating in subsequent seasons, particularly in Machakos. ${ }^{9}$

In view of these outcomes, there is a need for the state to identify more efficient strategies for targeting resource-poor farmers, with minimal leakages to the non-poor. The programme also must find ways of increasing participation of agro-dealers, particularly those operating at a small and medium scale, for instance by allowing them to form partnerships. Finally, there is an urgent need to simplify the voucher redemption process, possibly by devolving it to the districts and/or contracting the redemption function to a private financial institution.

\section{Limits of the agro-dealer model}

As the ASP and NAAIAP cases reveal, agrodealers face several challenges in the course of their trade, and this limits their effectiveness in 
providing inputs and information to producers and hence delivering the Green Revolution in Kenya. The first is a seed industry-wide challenge occasioned by weaknesses in the regulatory framework. For instance, the Seed and Plant Varieties Act (Cap 326) has not been reviewed since the industry was liberalised. It has, in the draft Seed Policy, been faulted for insufficiently addressing seed certification and testing; regional harmonisation of seed laws, regulations and policies; and review of legal framework. This affects seed trade in general and consequently, agro-dealership. Industry players (under the umbrellas of the Seed Trade Association of Kenya (STAK), which represents the interests of registered seed enterprises in the country, and the Plant Breeders Association of Kenya (PBAK), which brings together professional breeders and institutions involved in the production and commercialisation of plant seed materials) have been pressurising the government to review the seed laws. For instance, the informal system was included in the initial draft law because the government recognised the large amount of seed being supplied from the system. But during subsequent deliberations, many seed companies were reluctant to let the informal seed system be included in the revised version of the law. They feared loss of market share due to the anticipated competition from a 'better organised' informal sector in the market. The Ministry of Agriculture took a strong stand and insisted on having the informal system well taken care of in the law, but intensive lobbying by the companies contributed to slowing down the process of enacting the law. Also, worries by the companies that the proposed penalties in the revised version were too punitive - and not conducive for their operations. The seed traders have an association, STAK, which is powerful in lobbying and has access to the government system.

The second challenge is the agro-dealers' lack of working capital to adequately stock or expand their businesses. As a result, many agro-dealers are unable to meet farmers' demand at the peak of planting season. This supports observations by GNFA/AGMARK and earlier research in Trans Nzoia by Nambiro et al. (2001) that lack of capital was the most important barrier to entering hybrid maize seed retailing. A separate study by Ayieko and Tschirley (2006) found that, due to lack of capital, agro-dealers order less stock, which increases their operational costs and results in higher input prices for farmers. This limitation was cited by agro-dealers and extension officers as the major challenge in implementation of a NAAIAP in the two districts examined in this study. Specifically, most small entrepreneurs are locked out of financial markets, limiting their potential for input business expansion, especially in the low rainfall areas.

The third challenge is the highly erratic input prices, especially in Machakos and other ASAL areas. Chianu et al. (2008) and Muhammad et al. (2003) attribute this to high supply prices and high transaction costs, resulting from long distances to input suppliers and poor infrastructure, especially roads. Due to the price behaviour, agro-dealers at the grassroots find it hard to convince farmers to purchase significant volumes of seed from them. Many poor farmers opt instead to buy small quantities of certified seed from them and use mainly non-certified seed purchased or bartered through informal networks to top up their seed supply.

Consequently, movement of seed stock is slow and sales are low, limiting business profitability and growth. This, according to Chinau et al. (2008) constrains the development of an efficient agro-dealership.

In response to this high seed pricing challenge, many unlicensed agro-dealers in Machakos District sell to a customer maize seed from a package they have tampered with, contrary to the law (Condition 5 on the Seed Sellers' Licence). One agro-dealer owner observed: '... some of my customers ask for $1 \mathrm{~kg}$ of maize seed at the price they can afford, yet most varieties are sold in $2 \mathrm{~kg}$ packs. For such customers, I carefully break the package in the presence of the customer and remove $1 \mathrm{~kg}$ of seed, which I pack in another container for the customer. The rest of the seed must remain in the original container for easy identification and acceptance by the next customer who demands $1 \mathrm{~kg}$ of the same variety.' This may be a wake-up call to seed companies to start marketing maize seed in packs that are smaller than $2 \mathrm{~kg}$ in Machakos.

A fourth challenge is the erratic nature of agricultural input demand resulting from unpredictable weather patterns. Many agrodealers interviewed for this study observed that this variability caused them to lose business opportunities when there is a sudden upsurge of 
demand, and incur losses when inputs stocks reach their 'sell-by' date (particularly seed and agrochemicals, which form an important component of agro-dealers' stock), due to slow movement occasioned by unexpected decline in demand. This challenge shows that low adoption of improved seeds and fertilisers in low rainfall areas is mainly linked to farmer concerns about risk and uncertainty associated with rainfall unreliability, as opposed to problems with input accessibility. Also, the choice of hybrid maize as the dominant crop to be promoted through agrodealer networks seems to negate farmers' preferences, especially in the complex, riskprone environments. In these areas, agriculture is highly diversified, not only as a strategy for mitigating environmental risks, but also because it offers a wide range of choice of crops that meet the dietary needs of the communities.

The fifth challenge is inadequate supply of inputs at the peak of planting season. Some agrodealers interviewed argued that when the rains set in, there is very high demand for seed by farmers and many traders suddenly start to stock seed. This causes the larger suppliers to run out of stock, yet it takes some time before they can restock to match the high demand. Kenya's Business Daily magazine reported that maize prices had shot to a three-month high in April 2011, as dealers enlarged their reserves amid a biting shortage of planting seeds that could cut this season's harvest. The shortage is also said to have been caused by sale of seeds meant for the Kenyan market, to traders from Burundi, Rwanda, Tanzania and Uganda (Andae and Ng'etich 2011).

However, addressing these technical challenges alone may not be enough to allow agro-dealers to catalyse Kenya's long-awaited Green Revolution. The larger problem has more to do with the agro-dealer model itself, which is focused on an elite version of agricultural innovation based on a narrow set of technologies that privilege a particular set of political-business interests. The mainstream Green Revolution narrative for Kenya sees agro-dealers at the centre of the action, and portrays them as the ideal smallscale private sector solution for delivering new technologies to Kenya's farmers. However, the survey of two districts - one high potential and the other low potential - shows some limitations of this simple narrative. These include:
- The uneven geographical coverage with relatively fewer 'legal' and well capitalised agro-dealers in the poorer, lower potential areas

- The focus of delivery on a limited number of seeds and varieties (mostly hybrid maize, adapted to medium and high rainfall areas)

- The dominance of a few large companies in the supply chain, with knock-on consequences for price competitiveness and technology diversity

- The limited technical knowledge by those serving in agro-dealerships

- The restrictive nature of regulations, which limits wider competition in the local market

- Underdeveloped infrastructural support, which increases operating costs and consequently input prices, especially in the low rainfall areas.

Thus, the universalising narrative of the pivotal role of agro-dealers in Kenya's Green

Revolution, presented by a strong and influential actor network at the centre of agricultural policymaking and financing in Kenya must be qualified. The alliance between philanthropic-, state- and NGO-funded initiatives and smallscale business creates a set of interests at the heart of the new Green Revolution project. This combines substantial external funding with highlevel political support and local elite interests. This is a powerful network, whose dominance of the agricultural policy agenda has grown significantly in recent years, with the agro-dealer model now firmly embedded in all key government strategies. While the narratives which sees support to the small-scale private sector - and particularly the iconic agro-dealer as a route to poverty reduction and the blossoming of a new 'Green Revolution' has many adherents. The realities on the ground, as shown above, suggest that the current approach is only a partial solution at best and therefore must be called into question. The concluding section draws out some of these qualifications and their policy implications.

\section{Conclusion}

Despite the tremendous diversity of Kenya's agro-ecological zones and its equally complex farming systems, a convergence of influential political, economic and institutional interests are pushing a singular technological solution to drive agricultural innovation: the agro-dealer. 
Although different actors - the state, philanthropic organisations, seed companies and NGOs - employ different marketing and service delivery approaches in their activities, depending on geographical region, there is a clear consensus on the role of the agro-dealer as the primary carrier of improved seeds to farmers. Even seed aid for vulnerable farmers in food insecure areas is moving towards 'market-based' approaches such as vouchers, which require the active participation of agro-dealers to redeem them for prescribed seeds and fertiliser.

Several key findings emanate from this study. First, both formal and informal seed systems are important channels for delivering cereal seeds to Kenyan farmers. The informal systems (which do not involve agro-dealers) provide seeds of local maize and other cereals to farmers in low rainfall and marginal areas in the Eastern region of the country, such as Machakos. The formal systems use agro-dealers in providing mainly improved maize seed to farmers in high rainfall areas of western and central regions of the country. Notwithstanding the importance of the informal systems to many small farmers, the legal, regulatory and policy frameworks, which are informed by international seed policies and conventions, tend to favour the formal systems. As a result, agro-dealers may only spur a Green Revolution for a select group of privileged producers, mainly maize farmers operating in higher rainfall areas like Uasin Gishu.

Second, many of Kenya's agro-dealer owners sell a wide range of commodities, including pesticides, veterinary drugs, animal feeds, building materials and general merchandise, not just seeds and fertiliser. This diversity of stock reflects a risk-coping mechanism for business survival, given the seasonal and erratic demand for agricultural inputs, and also helps in spreading out business costs such as those associated with transport, handling and storage. Therefore, any initiatives aimed at supporting agro-dealers should not focus only on seed and fertilisers, but the totality of the business.

Another important finding is that less than a half of agro-dealer owners are involved in day-today management of their businesses, and are therefore unavailable to field technical queries from customers. Thus, the trainings in agrodealer capacity building programmes should not only focus on the business owners, they should also target the 'managers', especially with respect to the technical modules.

Finally, significant investments have gone into building the agro-dealer network in Kenya, through a number of new public and private programmes that have put agro-dealers at the centre of the new Green Revolution 'project'. These initiatives are based on narratives that frame the problem of low agricultural productivity in terms of farmers' lack of access to modern inputs (specifically improved seeds and fertilisers). The actors implementing these programmes see an increase in agro-dealer density as key to increasing accessibility of inputs and therefore have undertaken building agrodealer networks in rural areas. There seems to be a general consensus among various actors that because poor farmers are unable to effectively participate in input markets, there is need to provide them with subsidised inputs in order to stimulate demand for the inputs. However, the actors are in favour of market-friendly approaches, which promote agro-dealership and condition farmers for input markets. The universalising of the agro-dealer narrative in the programmes overlooks the heterogeneity of the smallholder farming population the agro-dealers must serve and the sheer diversity of agroecological and business environments in which they must operate. This complexity presents an enormous challenge for effective beneficiary targeting and leads to disproportionate 'wins' for farmers in higher rainfall, 'breadbasket' areas and for larger, well-connected agro-dealers fortunate enough to operate in those places.

In this article, we have argued that greater attention must be paid to meeting the needs of smallholder farmers in lower potential areas (who represent the vast majority of Kenya's agricultural producers) by developing innovative alternatives to the archetypal agro-dealer model promoted by programmes such as AGRA's ADDP and the Government of Kenya's NAAIAP, which focuses on a single entrepreneur capable of running a profitable business from the sale of agricultural inputs to a customer base, which is willing and able to afford them. Such alternative models would focus on the sale of complementary non-agricultural products or services with agricultural inputs to create a successful business or the establishment of group-based agro-dealerships, e.g. for farmers' 
organisations, women's groups or youth groups which might operate part-time or on a not-forprofit basis as a service to their communities. Furthermore, mobile agro-dealers might provide regular or periodic services to more remote areas than cannot sustain permanent agro-dealerships (possibly coming on market days when large numbers of people gather together). In short,

\section{Notes}

1 The Kenya's Vision 2030: A Globally Competitive and Prosperous Kenya document can be found at: www.safaricomfoundation.org/fileadmin/templ ate/main/downloads/Kenya_VISION_2030final_report-October_2007.pdf (accessed 30 April 2011).

2 Source: Interview with NAAIAP Programme Coordinator; and NAAIAP Programme Design and Implementation Framework 2009/2010.

3 For accreditation, stockists must have been in inputs business for one year; be registered with registrar of societies; certified by KEPHIS and PCPB; Kenya Revenue Authority (KRA) compliant; certified by

GNFA/AGMARK and recommended by their respective Development Assistance Committees.

4 Interview with NAAIAP Coordinator, Mr P. Makheti.

5 Farmers can access this facility through the Equity Bank at a 10 per cent interest rate, which is lower than average commercial

\section{References}

AGRA (2010) AGRA Partnerships and Programs Kenya, August 2010, www.agra-alliance.org/ section/about/grants\# agro (accessed 30 April 2011)

AGRA (2009a) Programme for Africa's Seeds Systems (PASS), www.agra-alliance.org/section/work/ seeds (accessed 26 November 2009)

AGRA (2009b) The Agro-dealer Development Programme, www.aec.msu.edu/fs2/zambia/ tour/AGRA_Agro_Dealer_Development_ Programme.pdf (accessed 15 July 2010)

Andae, G. and Ng'etich, P. (2011) 'Maize Prices Hit Three-Month High as Seed Shortage Persists', Business Daily, www.businessdailyafrica.com/ Maize + prices + hit + three + month + high + as + seed+shortage + persists/-/539552/1146124/ -/13jnc43z/-/index.html (accessed 30 April 2011)

Argwings-Kodhek, G.; Kwamboka, M. and Karin, F. (2004) Feast and Famine: Financial Services for Rural Kenya, Working Paper 12, Nairobi: efforts must be made to move away from the 'one-size-fits-all' agro-dealer model as it is currently construed. These and other alternative models must be found especially for the lower potential agricultural areas to complement or even replace the 'standard model' if the Green Revolution is to be delivered to the majority of Kenya's farmers.

lending rates. The credit is in the form of inputs acquired from CNFA/AGMARK certified agro-dealers. The agro-dealers later claim from Equity the money for inputs supplied to farmers.

6 Interview with extension officers in all the eight new districts carved out of the larger Machakos District.

7 Interviews with members of Kiomo Maize Growers' Group in Kangundo District, and a group of NAAIAP beneficiaries in Mwala District. (Both districts have been carved out of the larger Machakos).

8 Extension officers estimated the current yields of maize to range between 15 and 30 $90 \mathrm{~kg}$ bags per acre, depending on the agroecological zone, while the potential is about $30-3590 \mathrm{~kg}$ bags per acre.

9 In Machakos, most agro-dealers who participated in NAAIAP in 2008 declined to participate in 2009 and the district had to engage large agro-dealers from outside the district (such as Nairobi) to supply inputs.

Tegemeo Institute of Agricultural Policy and Development

Ayieko, M.W. and Tschirley D.L. (2006) Enhancing Access and Utilization of Quality Seed for Improved Food Security in Kenya, Working Paper 27, Nairobi: Tegemeo Institute of Agricultural Policy and Development

Chianu, J.N.; Mairura, F.; Ekise, I. and Chianu, J.N. (2008) 'Farm Input Marketing in Western Kenya: Challenges and Opportunities', African Journal of Agricultural Research 3.3: 167-73

Freeman, H.A. and Omiti, J.M. (2003) 'Fertilizer Use in Semi-Arid Areas of Kenya: Analysis of Smallholder Farmers' Adoption Behavior Under Liberalized Markets', Nutrient Cycling in Agroecosystems 66: 23-3

IFAD (2006) Statement by Lennart Båge, IFAD

President, Heads of State Session, Africa Fertilizer Summit, Abuja, 9-13 June 2006, www.ifad.org/events/op/2006/fertilizer.htm (accessed 15 July 2010) 
Kibaara, B.; Ariga J.; Olwande, J. and Jayne, T.S. (2009) Trends in Kenyan Agricultural Productivity: 1997-2007, Working Paper 31, Nairobi:

Tegemeo Institute of Agricultural Policy and Development

Muhammad, L.; Njoroge, K.; Bett, C.; Mwangi, W.; Verkuijl, H. and De Groote, H. (2003) The Seed Industry for Dryland Crops in Eastern Kenya, Mexico D.F.: CIMMYT and Kenya Agricultural Research Institute (KARI)

Nambiro, E.; de Groote, H. and Kosura, W.O. (2001) 'Market Structure and Conduct of the Hybrid Maize Seed Industry. A Case Study of the Trans Nzoia District in Western Kenya', in D.K. Friesen and A.F.E. Palmer (eds), (2004) Integrated Approaches to Higher Maize Productivity in the New Millennium: Proceedings of the Seventh Eastern and Southern Africa Regional Maize Conference, 5-11 February, Nairobi: CIMMYT (International Maize and Wheat Improvement Centre) and KARI (Kenya Agricultural Research Institute)

Nyangito, H.O (2008) Small Farmer Participation in Export Production: The Case of Kenya, Rome: Food and Agriculture Organisation of the United Nations

Nyoro, J.K. (2002) Agriculture and Rural Growth in Kenya, Nairobi: Tegemeo Institute of Agricultural Policy and Development
Omamo, S.W. and Mose, L.O. (1999) Fertilizer Trade Under Market Liberalisation: Preliminary Evidence from Kenya, Working Paper 1, Nairobi: Tegemeo Institute of Agricultural Policy and Development/Egerton University, Kenya Agricultural Research Institute and Michigan State University

Owuor, J. (1999) Determinants of Agricultural Productivity in Kenya, Nairobi: Tegemeo Institute of Agricultural Policy and Development/Egerton University, Kenya Agricultural Research Institute and Michigan State University

Republic of Kenya (2009) The National Accelerated Agricultural Input Access Program (NAAIAP): Program Design and Implementation Framework 2009/2010, Nairobi: Ministry of Agriculture Republic of Kenya (2007) Vision 2030: A Globally Competitive and Prosperous Kenya, Nairobi: Government of Kenya

Republic of Kenya (2004) Strategy for Revitalizing Agriculture 2004-2014, Nairobi: Ministry of Agriculture and Ministry of Livestock and Fisheries Development, Government of Kenya Rockefeller Foundation (2009) Fertilizer Toolkit: Promoting Efficient and Sustainable Fertilizer Use in Africa, www.worldbank.org/afr/fertilizer_tk/ documentspdf/RockefellerAgroDealerSupport. pdf (accessed 15 July 2010) 